\title{
Biodiversity and the Functioning of Ecosystems in the Age of Global Change: Integrating Knowledge Across Scales
}

\author{
Francisco R. Barboza, Maysa Ito, and Markus Franz
}

\begin{abstract}
The dramatic decline of biodiversity worldwide has raised a general concern on the impacts this process could have for the well-being of humanity. Human societies strongly depend on the benefits provided by natural ecosystems, which are the result of biogeochemical processes governed by species activities and their interaction with abiotic compartments. After decades of experimental research on the biodiversity-functioning relationship, a relative agreement has been reached on the mechanisms underlying the impacts that biodiversity loss can have on ecosystem processes. However, a general consensus is still missing. We suggest that the reason preventing an integration of existing knowledge is the scale discrepancy between observations on global change impacts and biodiversity-functioning experiments. The present chapter provides an overview of global change impacts on biodiversity across various ecological scales and its consequences for ecosystem functioning, highlighting what is known and where knowledge gaps still persist. Furthermore, the reader will be introduced to a set of tools that allow a multi-scale analysis of how global change drivers impact ecosystem functioning.
\end{abstract}

\section{What We Know and What We Do Not: Biodiversity and Functioning in the Anthropocene}

Environmental changes have ruled the geological history of Earth and have been responsible for the shifts that life has undergone during the past 3.5 billion years (Hoegh-Guldberg and Bruno 2010). Alternations between glacial and intergla-

F. R. Barboza $(\bowtie) \cdot$ M. Ito $\cdot$ M. Franz

GEOMAR Helmholtz Centre for Ocean Research, Kiel, Germany

e-mail: fbarboza@geomar.de; mito@geomar.de; mfranz@geomar.de cial episodes, tectonic activity, and abrupt changes in atmospheric and oceanic chemistry have promoted five massive extinctions in the last 500 million years (Barnosky et al. 2011 and citations therein). These catastrophic events, each of which killed more than three-quarters of existing biota in a period of less than 2 million years, erased or dramatically rearranged ecosystems worldwide (Hull 2015). The expansion of the human population since the beginning of the Industrial Revolution in the nineteenth century, and its acceleration between the 1940s and 1960s, is severely altering the biogeochemistry of our planet (Vitousek et al. 1997; Doney 2010). Imposed anthropogenic pressures on natural ecosystems are so extreme that the projected magnitude of their effects is only comparable with those observed during massive extinctions (Barnosky et al. 2011). Degradation and loss of habitats, biological invasions, overexploitation of natural resources, pollution, and climate change are driving an unprecedented loss of biodiversity at a global scale (Pimm et al. 2014).

Humans, being unique in terms of the scale of their impacts, are as vulnerable as any other species to changes in the ecosystems to which they belong. Human societies rely on the goods and services provided by the functioning of ecosystems, which depends on the cycling of matter and flux of energy that the interactions of living and non-living compartments make possible (Díaz et al. 2006). Thus, direct impacts of global change stressors on biogeochemical processes (e.g., excessive increase of nutrient loads in land and waters) or those mediated by the loss of biodiversity, alter the dynamics and functioning of ecosystems compromising the well-being of humans (Isbell et al. 2017). The consequences that the current rates of biodiversity loss could have on ecosystem services called for research on the role that biodiversity plays in determining the structure, functioning and stability of ecosystems (Cardinale et al. 2012). The extensive body of theoretical, observational, and experimental evidence generated in the last decades, has led to a certain 
consensus on the following set of statements, trends and potential underlying mechanisms:

\section{Biodiversity Increases Stability at the Ecosystem}

Level The diversity-stability debate is probably one of the most relevant - given its implications in light of the anthropogenic-induced loss of biodiversity - and long standing ones in Ecology (McCann 2000). The pioneering observational works of Odum (1953) and Elton (1958), awakened this discussion by acknowledging that simplified terrestrial communities (e.g., in agricultural systems) exhibit stronger fluctuations and are more vulnerable to biological invasions. Blindly accepted until the beginning of the 1970s, these statements were questioned by a series of thoughtful mathematical essays developed by Robert May (May 1971, 1972, 1973). The linear stability analysis of constructed random communities ${ }^{1}$ showed that the higher complexity is (in terms of connectance, strength of interaction and number of interacting species) the more unstable ${ }^{2}$ population dynamics will be. May's arguments, and beyond the unrealistic assumptions of the proposed models (i.e., communities are randomly structured and exhibit stable equilibrium dynamics, McCann 2000), highlighted the absence of a mechanistic understanding of existing empirical evidence. In other words, if more diverse natural ecosystems tend to be more stable but those randomly constructed are not, natural ecosystems must be structured by a set of non-random principles that determine their stability. The challenge raised by May's results triggered the search for a set of properties capable of conferring stability to complex ecological systems. The accumulated evidence by the analysis of empirical ecological networks highlighted, for example, the role of weak interactions and modularity as properties that prevent the spread of disturbances (Paine 1992; McCann et al. 1998; Neutel et al. 2002; Olesen et al. 2007; Gilarranz et al. 2017). ${ }^{3}$ A large body of empirical evidence supporting the diversity-stability relationship has been generated in the last four decades (McNaughton 1977; Stachowicz et al. 2007; Tilman et al. 2014). The manipulation of species or functional richness has shown that diversity reduces the temporal variability in the structure and functioning of communities (e.g., measured as biomass production). A remarkable conclusion of the syn-

\footnotetext{
${ }^{1}$ Theoretical communities where the type and magnitude of the interactions are defined using statistical distributions (see May 1972 for a brief but enlightening summary).

${ }^{2}$ Original works of Robert May define stability in terms of resilience, assuming that stable systems are those able to return to the equilibrium after a perturbation (see McCann 2000).

${ }^{3}$ The list of features mentioned for ecological networks is far from being exhaustive, but a detailed presentation of described topological patterns and underlying mechanisms is out of the scope of the present chapter. In this sense, we recommend Montoya et al. (2006) and Ronney and McCann (2012) for a general overview of the state of the art in food webs theory.
}

theses of these results is that the positive correlation between diversity and stability at the community level cannot necessarily be extended to single populations (Gross et al. 2014; Tilman et al. 2014). Alternative hypotheses have been proposed to account for these results (Yachi and Loreau 1999; Lehman and Tilman 2000). The averaging and covariance effects predict that the variability of the overall community will be dampened due to the balance between contrasting single species dynamics (Lehman and Tilman 2000). These hypotheses assume that the higher the diversity, the higher the probability of observing species that respond differentially to conditions and disturbances (McCann 2000). Furthermore, the insurance hypothesis added the idea that the higher the diversity, the higher the probability of having functionally redundant species. Thus, the loss of species with particular functions can be replaced by others, increasing the temporal stability of ecosystems' functioning (Yachi and Loreau 1999). All in all, existing theoretical and experimental evidence provided a potential solution to the diversitystability debate: the stabilizing effects of biodiversity at the ecosystem level (i.e., the observations of Odum and Elton) can occur at the expenses of decreasing single species stability (i.e., the theoretical conclusions of May) (Lehman and Tilman 2000).

\section{Biodiversity Increases the Efficiency and Productivity of}

Ecosystems The number of observational and experimental studies analyzing how changes in biodiversity impact the functioning of ecosystems has rapidly increased since the 1990s. Research across ecosystems (from terrestrial to marine) and considering diversity at different levels of biological organization (from genes to functional groups) has been developed worldwide. Recent meta-analyses have summarized available bibliography, obtaining conclusive evidence that, on average, the decrease of biodiversity is translated into altered ecosystem functions (e.g., a lower capacity of communities to use resources and produce biomass, see Cardinale et al. 2012 and citations therein). Regardless of the clarity of these findings, a consensus on the responsible mechanisms is still elusive. The selection effect (i.e., the prevalence of species with certain traits in the determination of ecosystem processes) and/or the complementarity effect (i.e., a better performance of the community due to an efficient partitioning of resources or facilitation among species) have been proposed for the explanation of biodiversity-functioning relationships (Loreau and Hector 2001). A sampling process ${ }^{4}$ is involved in both mechanisms, which means that the higher the diversity, the higher the odds

\footnotetext{
${ }^{4}$ In light of the existing literature, it is important to draw the attention of the readers on the fact that the sampling and selection effects, sometimes, are incorrectly used as interchangeable concepts. Please see Loreau and Hector (2001) for a clear explanation of the differences.
} 
of sampling a dominant species with specific traits or a set of species with complementary traits (Loreau and Hector 2001; Fargione et al. 2007). In light of these mechanisms, most of the empirical research developed in the last 10 years focused on disentangling the relative contribution of community composition (i.e., role of the taxonomic and/or functional identity of species) and complementarity to the effect of biodiversity on ecosystem processes. Cardinale et al. (2012) estimated an even contribution of both mechanisms, but highlighted that available evidence is still fragmentary for solving this debate.

Functional Diversity Determines Ecosystem Processes and Services Changes in biodiversity at all levels of biological organization could affect, to a greater or lesser extent, the functioning of ecosystems (e.g., Reusch et al. 2005; Worm et al. 2006). Nevertheless, there is a general agreement that functional diversity is the dimension of biodiversity that contributes the most to the determination of ecosystem processes (Díaz and Cabido 2001). Traits determine how species capture and use different resources, and interact with the environment. Thus, the role of species in the flux of energy and cycling of matter is shaped by their traits, being the identity, abundance, and range of these traits what links species and ecosystems from a functional perspective (Fig. 1; Naeem 1996; Bengtsson 1998). The goods and services provided by ecosystems depend on the persistence of biogeochemical processes, which rely on functional groups (i.e., sets of species that exhibit certain functional traits). It is the loss of functional groups, beyond species, ${ }^{5}$ that compromises the capacity of ecosystems to continue providing benefits to humanity (Díaz et al. 2006). During mass extinctions, and the current one is not the exception, the loss of species is driven by negative selection against certain traits. Thus, identifying traits that determine a greater extinction risk, and how they directly or indirectly (through the correlation with other traits) influence ecosystem processes, is essential to predict the consequences of extinctions on ecosystem services (Cardinale et al. 2012, Fig. 1).

The information gathered so far has certainly been valuable for describing the effects that biodiversity has on ecosystem functioning (among other ecosystem characteristics) and elucidating the underlying mechanisms that mediate these effects. Nevertheless, a scale discrepancy still persists

\footnotetext{
${ }^{5}$ It is important to clarify that keystone species (i.e., species with a disproportionately effect on the functioning of the ecosystem in comparison to its abundance) can be considered as single-species functional groups, since they are fully non-redundant and non-replaceable (Bond 1994).
}

between the local nature of the evidence on which the current understanding of the biodiversity-functioning relationship is held and the global scale at which the impacts of anthropogenic activities on biodiversity have usually been described (Isbell et al. 2017). The understanding of the potential cascading effects that large-scale changes in biodiversity might have on ecosystems at a local scale is a challenge that still needs to be addressed. In general, data have been generated in a fragmented way at different spatial, temporal and ecological scales. In addition, there are almost no attempts in the literature to integrate this knowledge (but see Isbell et al. 2017 for an example with a management background). In a context where current methodological constraints prevent "multi-scale" observational and experimental analyses of certain phenomena and processes, theoretical essays and modeling provide a powerful approach to bridge isolated empirical efforts. Thus, constructing on the existing bibliography, this chapter will give an integrated perspective of the impacts that global change drivers will have at different ecological scales - from regional species pools to the interaction between species in local communities - and their potential consequences on the functioning of ecosystems (Fig. 1). Beyond the literature review, we introduce a set of tools which allow a holistic analysis of the consequences that changes in biodiversity have on ecosystem processes under global change.

\section{Regional Pools of Species Under Global Change: Is Biodiversity Decreasing?}

Regional species pools are defined as the overall set of species that can colonize local communities. ${ }^{6}$ The total number of species observed in these pools is the result of the balance between processes that increase (i.e., speciation and immigration) and decrease (i.e., extinction) species diversity (Cornell and Harrison 2014). Human activities have heavily altered these processes mainly by increasing the rates of extinction and immigration. On one hand, the overexploitation of species of economic interest, the rapid and in many cases irreversible loss of habitat and the reduction of distributional ranges due to changes in prevailing climatic conditions are responsible for the loss of species at a regional scale. On the other hand, the dissemination of species out of their native range has promoted the exchange of species among previously isolated regions and in consequence the introduction of exotic species (Sax and Gaines 2003). The arrival and establishment of new species could have two

\footnotetext{
${ }^{6}$ Recent reviews and perspective articles have extensively discussed the regional species pool concept. We recommend Carstensen et al. (2013) and Cornell and Harrison (2014) for an overview on the topic.
} 


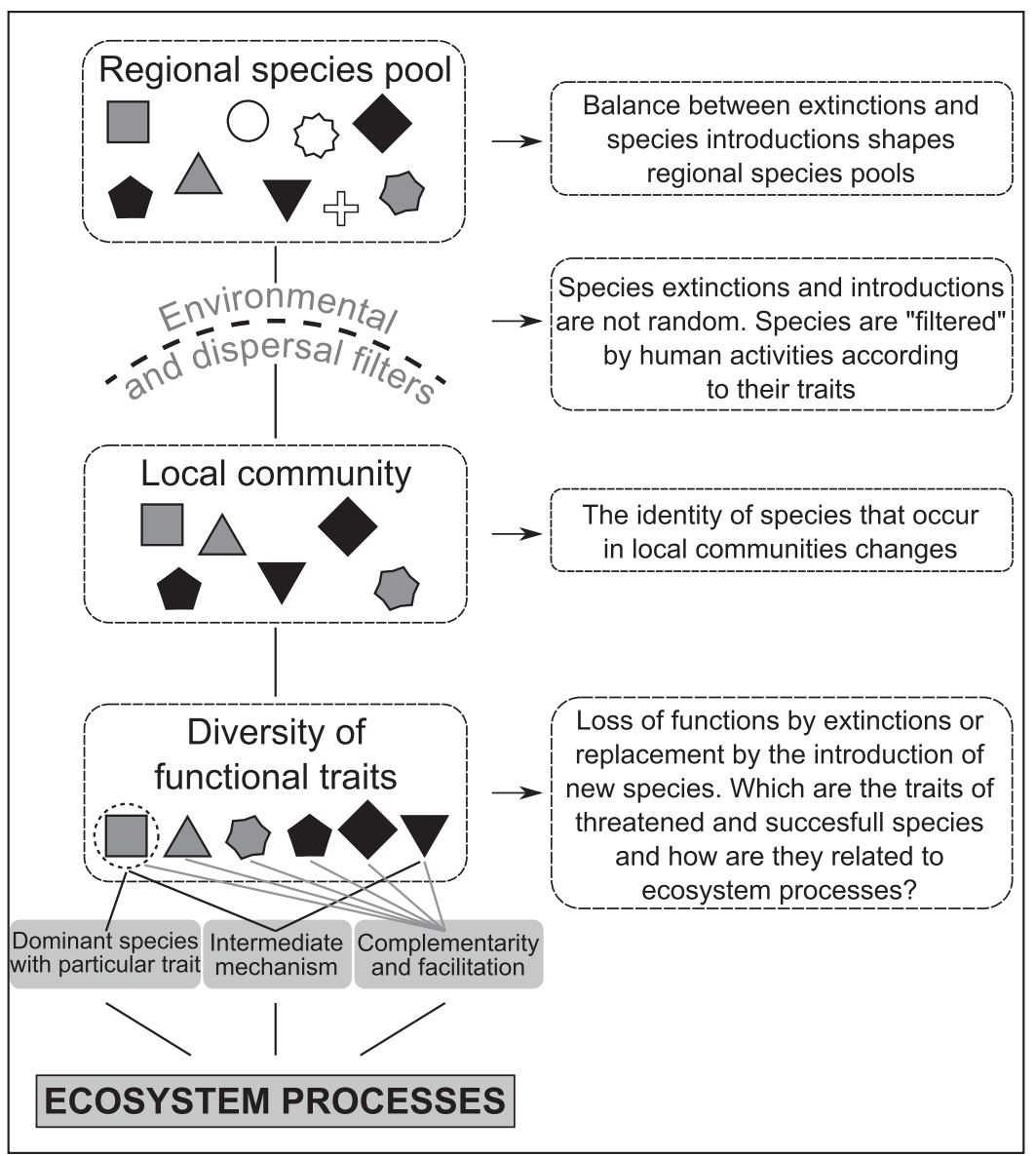

Fig. 1 Conceptual scheme integrating current knowledge on how biodiversity determines ecosystem functioning and expected cascading impacts of global change drivers.

The left side of the scheme (Adapted from Loreau et al. 2001) depicts a regional pool integrated by a set of species (represented by different shapes) with a range of functional traits (represented by different colors). From this initial set, only those species with particular traits can cope with experienced environmental and dispersal filters, occurring in a theoretical local community (i.e., only certain colors are observed in the community). The spectra of retained traits (functional diversity)

potential consequences on the diversity of a region: i) increase it due to the occurrence of a species that was not present within the original pool and that could even facilitate the arrival of other species or ii) diminish it by promoting the loss of native species through competition or predation (Sax and Gaines 2003, 2008), exceeding the gain that the introduction of a new species implies. ${ }^{7}$ Even though the vast majority of articles have focused on the negative consequences of exotic species, some authors are discussing the introduction of species from a new perspective. Recent

\footnotetext{
${ }^{7}$ An additional possibility will imply the generation of new species (and eventually new functional traits) by hybridization between native and non-native species. Please see Seehausen (2004) for a broad revision on the topic.
}

determines the ecosystem processes and services provided by the community. A gradient of explanatory mechanisms, with selection and complementarity effects as extremes, have been suggested to explain how changes in functional diversity alter ecosystem processes (see details in the main text). The right side shows structuring mechanisms (species extinctions and introductions) that are being enhanced in the course of global change across ecological scales. Imposed anthropogenic pressures modify functional diversity in a non-random way, making it possible to predict how ecosystem processes will change during the Anthropocene

works showed that from those species classified as endangered or extinct by the IUCN, a small percentage have exotic species as the main or single cause of decline (the numbers increase if only island regions are considered; Gurevitch and Padilla 2004; Sax and Gaines 2008). Much of the evidence on the negative impacts of exotic species is correlational (or based on small scale experiments) and it cannot be discarded that the spread of the new species was favored by the impacts of other drivers on native communities. In addition, worldwide evidence suggests that the number of species introduced in a given region exceeds the number of extirpated ones, generating on average an increase of species richness at the regional scale (Thomas 2013a, b). Therefore, what at a global scale is only determined by the balance between speciation and extinction, at a regional scale it is 
also shaped by the influx of new species that can compensate (regarding the number of species) extinctions or even generate an overall increase of regional diversity. But, as mentioned previously in this section, species richness is not the only dimension of biodiversity and the arrival of new species does not necessarily guarantee the functional replacement of extinct ones. In this context, it is crucial to better understand: (i) which are the traits of extirpated and introduced species, (ii) to what extent do they functionally overlap and (iii) if introduced species will be able to keep the functioning of ecosystems (Fig. 1).

\section{Functional Diversity in Local Communities: Are Species Lost Functionally Replaced by Those Introduced?}

As previously stated, human driven extinctions are not random, because certain species traits are favored or hampered by anthropogenic pressures, which act as environmental filters (Hillebrand and Blenckner 2002; Fig. 1). Traits like body size, fecundity, motility and physiological tolerance, among others, have been identified as potential predictors of both species' extinction risk and capacity to spread and colonize new environments. In this sense, it has been suggested that large body size, low fecundity, slow dispersal and resource specialization are generally filtered out, while small, fast reproducing, wide spreading, and generalist species are favored (McKinney and Lockwood 1999). According to these observations, it has been proposed that in the spectrum of variability of these traits, threatened and successful species must be in opposite extremes. Thus, those traits positively correlated with extinction risk must be negatively correlated with the probability of a species to get established and successfully spread (Blackburn and Jeschke 2009). This hypothesis, known as "two sides of the same coin", has been tested in terrestrial and aquatic environments for different taxonomic groups (fish, crustaceans, birds, reptiles and plants) (e.g., Murray et al. 2002; Marchetti et al. 2004; Blackburn and Jeschke 2009; Larson and Olden 2010; van Kleunen et al. 2010). The use of different definitions for invasive, non-invasive, threatened and rare species across articles, promoted the generation of contradictory evidence (van Kleunen and Richardson 2007; Blackburn and Jeschke 2009). Despite the methodological inconsistencies observed in the literature, it is still possible to draw some conclusions. The assumption that for all functional traits analyzed, threatened and successful species will always exhibit contrasting variants is an oversimplification (Tingley et al. 2016). The majority of the traits evaluated in the bibliography show small or no-difference among threatened and successful species (e.g., Jeschke and Strayer 2008; Tingley et al. 2016). It is important to highlight that the still fragmentary nature of the data for certain species could explain some of the obtained results (van Kleunen and Richardson 2007).

The current "absence" of trends in multiple-trait analyses questions the validity of the "two sides of the same coin" hypothesis (Jeschke and Strayer 2008; Blackburn and Jeschke 2009; Tingley et al. 2016). Available evidence makes it extremely difficult to speak about a set of traits that unequivocally predicts both extinction risk and species success, across environments and taxa. Nevertheless, results become more consistent if we just focus on extinctions (a process that has received much more attention in the last decades) and some specific traits. In particular, ecological and paleontological literature identified body mass as a major predictor of extinctions, i.e., large-bodied species are more likely to disappear. Body size tightly correlates with different life history traits and demographic characteristics determining the susceptibility of species to extinctionpromoting drivers (e.g., Purvis et al. 2000; Springer et al. 2003; Barnosky 2008). ${ }^{8}$ Important functional traits like trophic position, diet width, and productivity scale with body size. Thus, extinctions modify the size distribution of communities being able to alter the stability and functioning of ecosystems (Woodward et al. 2005). Observational and experimental examples have shown the consequences that the loss of "big" species has on ecosystem processes. Solan et al. (2004) showed that the loss of larger infaunal species reduces bioturbation and sediment oxygenation, altering the decomposition of organic matter and cycling of nutrients. Articles showing cascading effects of large predator's extinctions on overall ecosystems are probably those that better exemplify the impacts of body size changes. Estes et al. (2011) and Ripple et al. (2014) (and citations therein), reviewed the literature highlighting the relevance of topdown controls in ecosystems. Carbon uptake in freshwater and marine ecosystems, nutrients accumulation in soils and waters or primary production in coastal areas are just some examples of ecosystems processes affected by the extinction of apex consumers.

The question that still remains to be answered is whether the massive number of exotic species introduced worldwide will be able to functionally replace those that are lost (Fig. 1). Available data are insufficient to explain extinctions and introductions in terms of species traits and to determine the consequences of changes in those traits on ecosystem processes. Increasing research efforts on this topic are needed to accurately predict how ecosystems will respond under global change.

\footnotetext{
${ }^{8}$ The single consideration of mean adult body size (as has been done in most of the existing bibliography) in the mechanistic understanding of ecological and evolutionary processes could be misleading, since species usually show dramatic ontogenetic changes in body size (see Woodward et al. 2005 and Codron et al. 2012).
} 


\section{Tools for Analyzing Functioning: From Single Species to Functional Traits}

Many studies that link biodiversity with ecosystem functioning have focused on different biodiversity metrics, multiple processes and ecological interactions (Reiss et al. 2009). The usage of experimental data and modeling has been discussed, since the combination of these approaches could allow the detection of early signs of functioning shifts due to predicted global change. In this section a set of tools for studying the functioning of ecosystems is proposed. First, we focus on dynamic energetic budget (DEB) for single-species analysis due to the importance of evaluating the contribution of each component of functional groups. Second, we illustrate the use of ecological network analysis (ENA) to study community-level interactions. Third, we suggest the use of loop analysis (LA) to investigate how external inputs affect ecosystems.

\section{Species Level Analysis Using the Dynamic Energy Budget (DEB) Model}

The first step for studying an ecosystem is to understand the contribution of each component since ecological processes can be related to multiple species and at the same time one species might be involved in multiple processes (Reiss et al. 2009). The DEB is an individual-based model proposed as a method to analyze the role of the individual into the functioning context.

Kooijman (2010) proposes the DEB model for analyzing energy fluxes within individuals (Fig. 2). The DEB theory is based on the first law of thermodynamics and assumes the conservation of energy and mass. The model focuses on three basic energy fluxes: assimilation, dissipation and growth. Assimilation is the inflow of energy that enters the reserve pool proportional to the surface area of the organism. It is represented by the feeding minus the material excreted via feces, in the case of heterotrophs. In photoautotrophs, assimilation refers to the acquisition of nutrients mainly by photosynthesis (Edmunds et al. 2011). The energy reserve is used by the organism for maintenance, growth and reproduction. Dissipation corresponds to maintenance processes that use part of the reserve, which will result in products released into the environment, i.e., respiration. Growth corresponds to the increase of body size. The model also includes energy from the reserve that is invested in reproduction.

The DEB model is ideal for integrating single-species experimental outcomes (Edmunds et al. 2011). The model connects data acquired from physiology and structure of the organisms, i.e., functional traits, to provide an overview of the species as a system. In addition, the DEB model is able to describe the impacts of disturbance, e.g., pollutants (Nisbet et al. 2000; van der Meer 2006). The model also allows the assessment of the organisms from larval to adult stage, e.g., Monaco et al. (2014) carried out experiments with the sea-star Pisaster ochraceus under different lifestages and determined the transitions according to body size. The empirical data was used to predict the responses (e.g., flow of energy from reserve, structure and gonads to biomass). However, to exploit the potential of DEB models, more experiments considering how the traits change under different environmental conditions (e.g., temperature) would be necessary. The analysis of energy fluxes under future environmental state may assist the prediction of how the species will respond to environmental shifts or even to the new regions where they can be introduced. Knowing how species will respond is crucial because the species may change (e.g., become more or less efficient in processing energy or even disappear), resulting in biodiversity reshuffling under the effect of global change drivers.

The software developed for the DEB model is called DEBtool $^{9}$ for Matlab. It enables the user to analyze ecophysiological data by calculating relationships between variables and check the model predictions.

Analyzing single-species systems corresponds to finding only one piece of the entire puzzle. Putting empirical data together using a DEB model has good potential for single species and population analysis but the usage for ecosystems is still not certain (Nisbet et al. 2000). Muller et al. (2009) used the DEB model for analyzing the flow of energy using carbon and nitrogen as currencies of an autotroph, a heterotroph, and the symbiotic interaction between them. However, for modeling the complex interactions of ecosystems we suggest ENA as a better approach.

\section{Ecological Network Analysis (ENA)}

In order to connect the species embedded into a system and their relationships with abiotic components, ENA is a useful tool. It increases the complexity of food web analysis by quantifying the flow of energy and including interactions with non-living compartments that are part of the ecosystem (Gaedke 1995; Fig. 2). Food web models depict topological webs, i.e., binary networks where the species are the nodes (compartments) and the connections between them are representations of "who eats whom". ENA analysis considers that the food webs are exchanging energy with and within non-living compartments as well (Magri et al. 2017). The analysis is considered weighted when it includes the infor-

${ }^{9}$ The software and additional information can be found here: http:// www.bio.vu.nl/thb/deb/deblab/ 


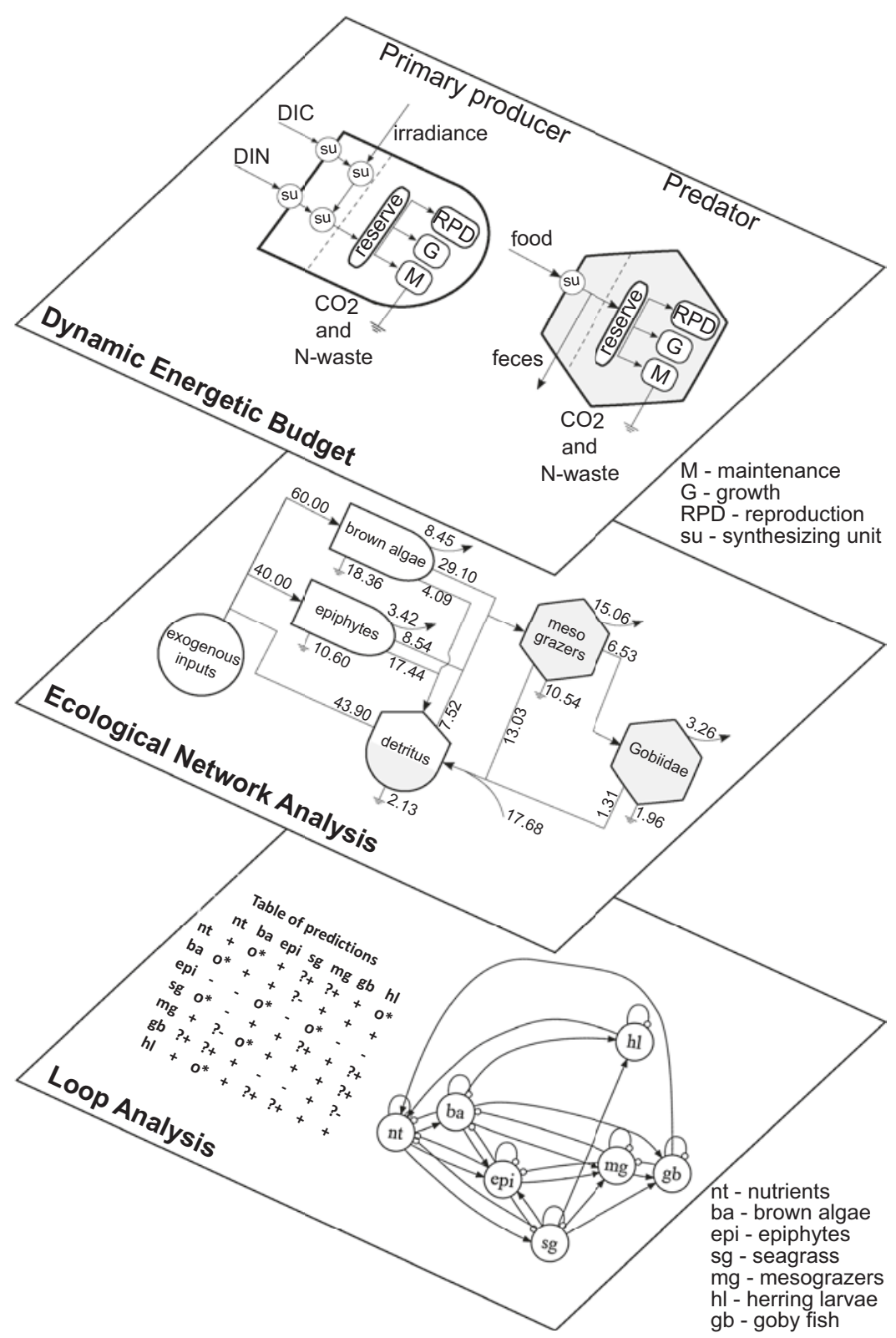

Fig. 2 Representation of the recommended tools for analyzing ecosystem functioning. The layers show that the analysis could target various organizational levels: single species (upper layer), ecological communities (in the middle), and interactions of ecological and human components, e.g., the increase of nutrient inputs in aquatic systems (lower layer).

The schematic representation of the upper layer refers to the dynamic energetic budget and illustrates the fate of energy flow in a primary producer and a predator. The (trophic) interactions between the species in the community are represented as ecological network analysis. The network traces carbon flows of a hypothetical coastal community of the Baltic Sea and the flows display matter circulation in terms of $\mathrm{mg} \mathrm{C} \mathrm{m}^{-2}$ day $^{-1}$. Finally, the loop analysis can bring together feeding interactions and other non-trophic relationships like symbiosis. In the hypothetical Baltic Sea community presented, the interactions of mesograzers and herring larvae with seagrass are related to habitat provision. Also, the brown algae and seagrass interactions with epiphytes are related to competition. The table of prediction for the community on the left side indicates the expected responses of column compartments following positive perturbations on the row compartments. The signed directed graph of the community on the right side of the loop analysis depicts positive interactions as arrows and negative interactions as empty circles 
mation about feeding rates, that represent the strength of the connections (Ulanowicz 2004). ENA (like the DEB model) assumes conservation of energy and mass (i.e., all nodes must be at steady-state, with the same amount of energy exchanged by input and output processes). Therefore, ENA considers four types of energy flows: imports, exports, respirations (i.e., losses) and inter-compartmental exchanges. The energy flow can be expressed in the unit kcal and various mediums (currencies) such as carbon, nitrogen, phosphorus, and sulfur. The input of energy into the system usually is related to the gross primary productivity or even detritus aggregation that enters the system. The loss of energy corresponds to degraded material that might be represented by dissipation as heat (i.e., respiration), which is different from the export of usable energy to other systems (e.g., detritus that is flushed away from an eelgrass meadow). The intercompartments corresponds to quantification of flows by energy transferred not only by the predator-prey interaction but also from living to non-living (and vice and versa) compartments (Kay et al. 1989). For example, this kind of analysis is useful for identifying cascade effects on the processes in an ecosystem. Indeed, ENA is able to connect information about the elements of the ecosystem to quantify how indirect effects spread along the system (Ulanowicz 2004). For example, ENA has been used for investigating changes due to eutrophication (Christian et al. 2009). One of the consequences detected was that eutrophication decreased the macrophyte biomass, lowering herbivory and causing impacts to the functioning of the overall system.

ENA is able to shed light on different aspects of ecosystem functioning. The algorithms of ENA provide indices that show how the systems respond to changes applied to them (Baird et al. 2004). Some output variables connected to the functioning of the systems are:

- The efficiency of the ecosystems in using the energy captured by primary producers can shift under different conditions (e.g., salinity gradients). The efficiency determines whether an ecosystem is more autotrophic or heterotrophic. The ENA provides the Lindeman spine, which is the representation of the complex network in terms of a linear food chain based on discrete trophic levels. It depicts the transfer of energy along compartments in a simplified way allowing the calculation of trophic efficiency (Baird and Ulanowicz 1993).

- Energy cycling can be a good indicator of stress (Ulanowicz 1995). Cycling refers to the recycling of the medium within the ecosystem, i.e., the ability of the nodes involved in the energy transfer to reuse the medium. In order to obtain a complete picture of the consequences of cycling it is important to analyze the number of cycles, length of the cycles (quantity of nodes involved) and species involved. The total amount of cycling is represented by the Finn cycling index (FCI). Mature ecosystems tend to have more cycles and increase the amount of energy circulating through them. However, eutrophication that represents a stress for ecosystems may also contribute to generate more cycles. The difference between mature and eutrophic systems is the length of these cycles. For example, mature ecosystems have longer cycles, while eutrophic systems present a high FCI but the cycles are shorter, so the energy does not reach higher trophic levels in the food web resulting in loss of functioning (Baird et al. 2004; Christian et al. 2005).

- Average residence time (ART) is related to the time that the medium is retained in the network. The residence time is not necessarily related to the aforementioned cycling since the intensity of the cycles (i.e., energy flowing within the cycles) can vary (Baird and Ulanowicz 1989). The ART is calculated by the ratio of the total system biomass and total output (Baird et al. 2004). The less time it spends in the system, the less efficient the system is in using energetic resources (Baird et al. 2004).

- Average path length expresses the quantity of compartments that the medium goes through before leaving the system. Shorter paths may be the response to stressful conditions in the ecosystem (Baird and Ulanowicz 1993).

- Total system throughput (TST) is related to the whole activity because it reports the amount of the medium flowing through the system. It is used to quantify ecosystems growth.

- Ascendency (A) corresponds to the organization (i.e., development) of the system considering the total activity (TST). It has also been suggested the use of "internal ascendency" $\left(\mathrm{A}_{\mathrm{I}}\right)$ that considers only internal flows of the studied system. Ulanowicz (2004) suggests $A_{I}$ for comparing growth and development of different ecosystems.

- Overhead takes into account the four types of flow while redundancy indicates the quantity of internal flows only. Both overhead and redundancy have been used to determine the resilience of the system. Increased values mean more resilient ecosystem according to Ulanowicz (2004).

- Development capacity is the upper limit of development that can be attained by ascendency. It is calculated as the sum of ascendency plus the overhead. It indicates the status of a system. Ascendency/development capacity ratios are good indicators of organization of the system (Ulanowicz 2004).

In order to use ENA for evaluating ecological processes and the impacts of environmental change, we have some recommendations. The first recommendation is to examine food webs throughout the seasons because the networks depict static snapshots of energy-matter flows in ecosystems. Traits of species such as body size, ontogeny and trophic interactions shift along the seasons (Warren 1989). Therefore, the 
simplification of the analysis (e.g., carrying out the ENA for the whole year) might lead to overlook patterns, e.g., cycling (Bondavalli et al. 2006). The analysis over the seasons is useful for studying temporal dynamics. Consequently, it helps to disentangle the changes driven by natural variability from stress, e.g., eutrophication (Bondavalli et al. 2006).

The second recommendation are the software tools for ENA, NETWRK 4.2 (Ulanowicz and Kay 1991) and Ecopath with Ecosim (Christensen and Pauly 1992). NETWRK 4.2 runs the ENA and the outputs include the indices and properties described above. It was written for DOS, however, there are Windows user-friendly versions like EcoNetwrk developed by NOAA Great Lakes Environmental Research Lab and WAND (Allesina and Bondavalli 2004). Ecopath is widely used for fishery management and includes intuitive functions to model incomplete dataset with algorithms that allow balancing the networks.

A final recommendation focuses on which data should be used to run the model, not only for ENA but also for DEB. Authors have used data from the literature and/or expert opinion only (Christian et al. 2009), but it could represent a limiting factor for the analysis. Although literature data is a valuable resource it is not possible to find updated data in many cases, which can alter the accuracy of the models. Therefore, we emphasize that generation of data broads the potential of the models. Experiments exposing organisms or even biological communities to environmental gradients or even testing the synergetic effects of possible stressors allow us to model the energetic flow and find optimal conditions for targeted organisms or ecosystems. Also the use of monitoring data is recommended in order to understand how the species or communities respond to seasonal or annual variability they go through. The use of experimental and monitoring data to feed the models enables us to understand the thresholds of tolerance range (plasticity) and make better predictions for future climatic changes and possible biological invasions.

\section{Towards Functional Trait Assessment Using Loop Analysis (LA)}

Even though ENA shows great potential for analyzing the functioning of ecosystems, there are some aspects that are not covered. The model is restricted to the application of only one type of currency to represent the interactions. When we refer to functional traits, the species may be grouped according to diverse characteristics depending on the function you are looking at. In this subsection, we aim to introduce the application of qualitative analysis as a tool to handle such complexity. In the same framework, it incorporates predator-prey, mutualistic and symbiotic relationships, while at the same time creating connections between human activi- ties and ecosystems (Dee et al. 2017). Qualitative analysis is able to predict the response of the ecosystems to inputs (disturbances), e.g., biological invasions (Raymond et al. 2011) and overfishing (Rocchi et al. 2016).

LA is a holistic and qualitative analysis that is based on positive, negative, and absence of interactions between nodes (Levins 1974). It allows predicting how the impacts from perturbations that occur on target nodes may propagate through the interaction network, thus generating indirect effects on other nodes of the system. It has been used for many purposes: from explaining the interactions between organisms in a food web (Bodini et al. 1994) to modelling the effects that ecological processes have on society (Martone et al. 2017). A loop or circuit is defined as a pathway that crosses the nodes only once and finishes where it started, creating positive or negative feedbacks (Fig. 2). The pathways and feedbacks are determined based on the interactions described in the literature (Bodini 2000). For our purpose, the most interesting part in the analysis is calculating the sign of the feedbacks, since LA detects the cascade effects of the inputs on the functioning and predicts whether the nodes are going to increase, decrease or remain the same under the impact of different perturbations (Bodini 2000). Levins (1974) showed that the systems are stable when there are more negative feedbacks than positive ones. The predictions generated by LA are displayed in a matrix that presents the response of all nodes to the positive input of each variable (Martone et al. 2017; Fig. 2). Software solutions to run these models are available as pakages in R and GUI versions. ${ }^{10}$ The software tools usually provide a matrix and a schematic figure (see Fig. 2) with the pathways and types of feedbacks that connect the nodes.

LA has proved to be a useful tool to bring together variables of different kind. Thus, as long as the type of interaction (positive, negative or neutral) is known, it can be a powerful tool to analyze the effect of functional traits independently on the functions used to define them. In addition, the traits can be connected to measure the efficiency of various management strategies, ecosystem functioning and services provided to society (Martone et al. 2017).

\section{Conclusions}

The functioning of ecosystems is modulated by the responses of different compartments (e.g., primary producers, herbivores), which determine how species interact. Thus, the horizontal analysis of single compartments using DEB models could help to understand the basis of ecosystems functioning. Nevertheless, a more holistic approach

\footnotetext{
${ }^{10}$ The software and additional information can be found here: https:// www.alexisdinno.com/LoopAnalyst/
} 
can be reached by integrating vertical analysis, i.e., how compartments influence each other by considering feeding preferences and the interaction with non-living elements in ENA. DEB and ENA are not necessarily meant to be used together, but they are complementary and using both of them may diminish uncertainties. Once we understood how the compartments of ecosystems behave, the LA might be the way to bring the discussion to another level. LA outputs can provide information about expected impacts of disturbances on the functioning and services provided by ecosystems. Literature attempting to ingrate the overall complexity of ecosystems and predict the expected consequences of global change drivers on their structure and functioning is still scarce. Hereby we suggest that this gap can be fulfilled based on rigorous algorithms and analytical methods.

\section{Appendix}

This article is related to the YOUMARES 8 conference session no. 6: "The Interplay Between Marine Biodiversity and Ecosystems Functioning: Patterns and Mechanisms in a Changing World". The original Call for Abstracts and the abstracts of the presentations within this session can be found in the appendix "Conference Sessions and Abstracts", chapter "11 The Interplay Between Marine Biodiversity and Ecosystems Functioning: Patterns and Mechanisms in a Changing World", of this book.

\section{References}

Allesina S, Bondavalli C (2004) WAND: an ecological network analysis user-friendly tool. Environ Model Softw 19:337-340. https://doi. org/10.1016/j.envsoft.2003.10.002

Baird D, Ulanowicz RE (1989) The seasonal dynamics of the Chesapeake Bay ecosystem. Ecol Monogr 59:329-364

Baird D, Ulanowicz R (1993) Comparative study on the trophic structure, cycling and ecosystem properties of four tidal estuaries. Mar Ecol Prog Ser 99:221-237. https://doi.org/10.3354/meps099221

Baird D, Christian RR, Peterson CH et al (2004) Consequences of hypoxia on estuarine ecosystem function: energy diversion from consumers to microbes. Ecol Appl 14:805-822. https://doi. org/10.1890/02-5094

Barnosky AD (2008) Megafauna biomass tradeoff as a driver of quaternary and future extinctions. Proc Natl Acad Sci U S A 105:1154311548. https://doi.org/10.1073/pnas.0801918105

Barnosky AD, Matzke N, Tomiya S et al (2011) Has the Earth's sixth mass extinction already arrived? Nature 471:51-57. https://doi. org/10.1038/nature09678

Bengtsson J (1998) Which species? What kind of diversity? Which ecosystem function? Some problems in studies of relations between biodiversity and ecosystem function. Appl Soil Ecol 10:191-199. https://doi.org/10.1016/S0929-1393(98)00120-6

Blackburn TM, Jeschke JM (2009) Invasion success and threat status: two sides of a different coin? Ecography 32:83-88. https://doi. org/10.1111/j.1600-0587.2008.05661.x
Bodini A (2000) Reconstructing trophic interactions as a tool for understanding and managing ecosystems: application to a shallow eutrophic lake. Can J Fish Aquat Sci 57:1999-2009. https://doi. org/10.1139/f00-153

Bodini A, Giavelli G, Rossi O (1994) The qualitative analysis of community food webs: implications for wildlife management and conservation. J Environ Manag 41:49-65. https://doi.org/10.1006/ jema.1994.1033

Bond WJ (1994) Keystone species. In: Schulze ED, Mooney HA (eds) Biodiversity and ecosystem function. Springer, Berlin/Heidelberg, pp 237-253

Bondavalli C, Bodini A, Rossetti G et al (2006) Detecting stress at the whole-ecosystem level: the case of a mountain lake (Lake Santo, Italy). Ecosystems 9(5):768-787. https://doi.org/10.1007/ s10021-005-0065-y

Cardinale BJ, Duffy JE, Gonzalez A et al (2012) Biodiversity loss and its impact on humanity. Nature 486:59-67. https://doi.org/10.1038/ nature 11148

Carstensen DW, Lessard JP, Holt BG et al (2013) Introducing the biogeographic species pool. Ecography 36:1310-1318. https://doi. org/10.1111/j.1600-0587.2013.00329.x

Christensen V, Pauly D (1992) ECOPATH II - a software for balancing steady-state ecosystem models and calculating network characteristics. Ecol Model 61:169-185. https://doi. org/10.1016/0304-3800(92)90016-8

Christian RR, Baird D, Luczkovich J et al (2005) Role of network analysis in comparative ecosystem ecology of estuaries. In: Belgrano A, Scharler UM, Dunne J et al (eds) Aquatic food webs: an ecosystem approach. Oxford University Press, Oxford, pp 25-40

Christian RR, Brinson MM, Dame JK et al (2009) Ecological network analyses and their use for establishing reference domain in functional assessment of an estuary. Ecol Model 220:3113-3122. https:// doi.org/10.1016/j.ecolmodel.2009.07.012

Codron D, Carbone C, Müller DWH et al (2012) Ontogenetic niche shifts in dinosaurs influenced size, diversity and extinction in terrestrial vertebrates. Biol Lett 8:620-623. https://doi.org/10.1098/ rsbl.2012.0240

Cornell HV, Harrison SP (2014) What are species pools and when are they important? Annu Rev Ecol Evol Syst 45:45-67. https://doi. org/10.1146/annurev-ecolsys-120213-091759

Dee LE, Allesina S, Bonn A et al (2017) Operationalizing network theory for ecosystem service assessments. Trends Ecol Evol 32:118130. https://doi.org/10.1016/j.tree.2016.10.011

Díaz S, Cabido M (2001) Vive la différence: plant functional diversity matters to ecosystem processes. Trends Ecol Evol 16:646-655. https://doi.org/10.1016/S0169-5347(01)02283-2

Díaz S, Fargione J, Chapin FS et al (2006) Biodiversity loss threatens human Well-being. PLoS Biol 4:e277. https://doi.org/10.1371/journal.pbio. 0040277

Doney SC (2010) The growing human footprint on coastal and openocean biogeochemistry. Science 328:1512-1516. https://doi. org/10.1126/science. 1185198

Edmunds PJ, Putnam HM, Nisbet RM et al (2011) Benchmarks in organism performance and their use in comparative analyses. Oecologia 167:379-390. https://doi.org/10.1007/s00442-011-2004-2

Elton CS (1958) The ecology of invasions by animals and plants, 1st edn. Chapman and Hall Ltd, London

Estes JA, Terborgh J, Brashares JS et al (2011) Trophic downgrading of planet earth. Science 333:301-306. https://doi.org/10.1126/ science. 1205106

Fargione J, Tilman D, Dybzinski R et al (2007) From selection to complementarity: shifts in the causes of biodiversity-productivity relationships in a long-term biodiversity experiment. Proc R Soc B 274:871-876. https://doi.org/10.1098/rspb.2006.0351

Gaedke U (1995) A comparison of whole-community and ecosystem approaches (biomass size distributions, food web analysis, network 
analysis, simulation models) to study the structure, function and regulation of pelagic food webs. J Plankton Res 17(6):1273-1305. https://doi.org/10.1093/plankt/17.6.1273

Gilarranz LJ, Rayfield B, Liñán-Cembrano G et al (2017) Effects of network modularity on the spread of perturbation impact in experimental metapopulations. Science 357:199-201. https://doi.org/10.1126/ science.aal4122

Gross K, Cardinale BJ, Fox JW et al (2014) Species richness and the temporal stability of biomass production: a new analysis of recent biodiversity experiments. Am Nat 183:1-12. https://doi. org/10.1086/673915

Gurevitch J, Padilla D (2004) Are invasive species a major cause of extinctions? Trends Ecol Evol 19:470-474. https://doi. org/10.1016/j.tree.2004.07.005

Hillebrand H, Blenckner T (2002) Regional and local impact on species diversity - from pattern to processes. Oecologia 132:479-491. https://doi.org/10.1007/s00442-002-0988-3

Hoegh-Guldberg O, Bruno JF (2010) The impact of climate change on the world's marine ecosystems. Science 328:1523-1528. https:// doi.org/10.1126/science.1189930

Hull P (2015) Life in the aftermath of mass extinctions. Curr Biol 25:R941-R952. https://doi.org/10.1016/j.cub.2015.08.053

Isbell F, Gonzalez A, Loreau M et al (2017) Linking the influence and dependence of people on biodiversity across scales. Nature 546:6572. https://doi.org/10.1038/nature22899

Jeschke JM, Strayer DL (2008) Are threat status and invasion success two sides of the same coin? Ecography 31:124-130. https://doi. org/10.1111/j.2007.0906-7590.05343.x

Kay JJ, Graham LA, Ulanowicz RE (1989) A detailed guide to network analysis. In: Wulff F, Field JG, Mann KH (eds) Network analysis in marine ecology. Springer, Berlin/Heidelberg, pp 15-61

Kooijman SALM (2010) Dynamic energy budget theory, 3rd edn. Cambridge University Press, Cambridge

Larson ER, Olden JD (2010) Latent extinction and invasion risk of crayfishes in the southeastern United States. Conserv Biol 24:10991110. https://doi.org/10.1111/j.1523-1739.2010.01462.x

Lehman CL, Tilman D (2000) Biodiversity, stability, and productivity in competitive communities. Am Nat 156:534-552. https://doi. org/10.1086/303402

Levins R (1974) Discussion paper: the qualitative analysis of partially specified systems. Ann N Y Acad Sci 231:123-138

Loreau M, Hector A (2001) Partitioning selection and complementarity in biodiversity experiments. Nature 412:72-76. https://doi. org/10.1038/35083573

Loreau M, Naeem S, Inchausti P et al (2001) Biodiversity and ecosystem functioning: current knowledge and future challenges. Science 294:804-808. https://doi.org/10.1126/science.1064088

Magri M, Benelli S, Bondavalli C et al (2017) Benthic N pathways in illuminated and bioturbated sediments studied with network analysis. Limnol Oceanogr 63:S68. https://doi.org/10.1002//no.10724

Marchetti MP, Moyle PB, Levine R (2004) Invasive species profiling? Exploring the characteristics of non-native fishes across invasion stages in California. Freshw Biol 49:646-661. https://doi. org/10.1111/j.1365-2427.2004.01202.x

Martone RG, Bodini A, Micheli F (2017) Identifying potential consequences of natural perturbations and management decisions on a coastal fishery social-ecological system using qualitative loop analysis. Ecol Soc 22:34. https://doi.org/10.5751/ES-08825-220134

May RM (1971) Stability in multispecies community models. Math Biosci 12:59-79. https://doi.org/10.1016/0025-5564(71)90074-5

May RM (1972) Will a large complex system be stable? Nature 238:413-414. https://doi.org/10.1038/238413a0

May RM (1973) Stability and complexity in model ecosystems, 1st edn. Princeton University Press, Princeton

McCann KS (2000) The diversity-stability debate. Nature 405:228233. https://doi.org/10.1038/35012234
McCann K, Hastings A, Huxel GR (1998) Weak trophic interactions and the balance of nature. Nature 395:794-798. https://doi. org/10.1038/27427

McKinney ML, Lockwood JL (1999) Biotic homogenization: a few winners replacing many losers in the next mass extinction. Trends Ecol Evol 14:450-453. https://doi.org/10.1016/S0169-5347(99)01679-1

McNaughton SJ (1977) Diversity and stability of ecological communities: a comment on the role of empiricism in ecology. Am Nat 111:515-525. https://doi.org/10.1086/283181

Monaco CJ, Wethey DS, Helmuth B (2014) A dynamic energy budget (DEB) model for the keystone predator Pisaster ochraceus. PLoS One 9(8):e104658. https://doi.org/10.1371/journal.pone.0104658

Montoya JM, Pimm SL, Solé RV (2006) Ecological networks and their fragility. Nature 442:259-264. https://doi.org/10.1038/nature04927

Muller EB, Kooijman SALM, Edmunds PJ et al (2009) Dynamic energy budgets in syntrophic symbiotic relationships between heterotrophic hosts and photoautotrophic symbionts. J Theor Biol 259:44-57. https://doi.org/10.1016/j.jtbi.2009.03.004

Murray BR, Thrall PH, Gill AM et al (2002) How plant life-history and ecological traits relate to species rarity and commonness at varying spatial scales. Austral Ecol 27:291-310. https://doi. org/10.1046/j.1442-9993.2002.01181.x

Naeem S (1996) Species redundancy and ecosystem reliability. Conserv Biol 12:39-45. https://doi.org/10.1111/j.1523-1739.1998.96379.x

Neutel A-M, Heesterbeek JAP, De Ruiter PC (2002) Stability in real food webs: weak links in long loops. Science 296:1120-1123. https://doi.org/10.1126/science.1068326

Nisbet RM, Muller EB, Lika K et al (2000) From molecules to ecosystems through dynamic energy budget models. J Anim Ecol 69:913926. https://doi.org/10.1046/j.1365-2656.2000.00448.x

Odum EP (1953) Fundamentals of ecology, 1st edn. Saunders Co., Philadelphia

Olesen JM, Bascompte J, Dupont YL et al (2007) The modularity of pollination networks. Proc Natl Acad Sci U S A 104:19891-19896. https://doi.org/10.1073/pnas.0706375104

Paine RT (1992) Food-web analysis through field measurement of per capita interaction strength. Nature 355:73-75. https://doi. org/10.1038/355073a0

Pimm SL, Jenkins CN, Abell R et al (2014) The biodiversity of species and their rates of extinction, distribution, and protection. Science 344:1246752. https://doi.org/10.1126/science.1246752

Purvis A, Gittleman JL, Cowlishaw G et al (2000) Predicting extinction risk in declining species. Proc R Soc B 267:1947-1952. https://doi. org/10.1098/rspb.2000.1234

Raymond B, McInnes J, Dambacher JM et al (2011) Qualitative modelling of invasive species eradication on subantarctic Macquarie Island. J Appl Ecol 48:181-191. https://doi. org/10.1111/j.1365-2664.2010.01916.x

Reiss J, Bridle JR, Montoya JM et al (2009) Emerging horizons in biodiversity and ecosystem functioning research. Trends Ecol Evol 24:505-514. https://doi.org/10.1016/j.tree.2009.03.018

Reusch TBH, Ehlers A, Hammerli A et al (2005) Ecosystem recovery after climatic extremes enhanced by genotypic diversity. Proc Natl Acad Sci U S A 102:2826-2831. https://doi.org/10.1073/ pnas.0500008102

Ripple WJ, Estes JA, Beschta RL et al (2014) Status and ecological effects of the world's largest carnivores. Science 343:1241484. https://doi.org/10.1126/science.1241484

Rocchi M, Scotti M, Micheli F et al (2016) Key species and impact of fishery through food web analysis: a case study from Baja California Sur, Mexico. J Mar Syst 165:92-102. https://doi.org/10.1016/j. jmarsys.2016.10.003

Rooney N, McCann KS (2012) Integrating food web diversity, structure and stability. Trends Ecol Evol 27:40-45. https://doi.org/10.1016/j. tree.2011.09.001 
Sax DF, Gaines SD (2003) Species diversity: from global decreases to local increases. Trends Ecol Evol 18:561-566. https://doi. org/10.1016/S0169-5347(03)00224-6

Sax DF, Gaines SD (2008) Species invasions and extinction: the future of native biodiversity on islands. Proc Natl Acad Sci U S A 105:11490-11497. https://doi.org/10.1073/pnas.0802290105

Seehausen O (2004) Hybridization and adaptive radiation. Trends Ecol Evol 19:198-207. https://doi.org/10.1016/j.tree.2004.01.003

Solan M, Cardinale BJ, Downing AL et al (2004) Extinction and ecosystem function in the marine benthos. Science 306:1177-1180. https://doi.org/10.1126/science.1103960

Springer AM, Estes JA, van Vliet GB et al (2003) Sequential megafaunal collapse in the North Pacific Ocean: an ongoing legacy of industrial whaling? Proc Natl Acad Sci U S A 100:12223-12228. https://doi.org/10.1073/pnas.1635156100

Stachowicz JJ, Bruno JF, Duffy JE (2007) Understanding the effects of marine biodiversity on communities and ecosystems. Annu Rev Ecol Evol Syst 38:739-766. https://doi.org/10.1146/annurev. ecolsys.38.091206.095659

Thomas CD (2013a) The Anthropocene could raise biological diversity. Nature 502:7. https://doi.org/10.1038/502007a

Thomas CD (2013b) Local diversity stays about the same, regional diversity increases, and global diversity declines. Proc Natl Acad Sci U S A 110:19187-19188. https://doi.org/10.1073/pnas.1319304110

Tilman D, Isbell F, Cowles JM (2014) Biodiversity and ecosystem functioning. Annu Rev Ecol Evol Syst 45:471-493. https://doi. org/10.1146/annurev-ecolsys-120213-091917

Tingley R, Mahoney PJ, Durso AM et al (2016) Threatened and invasive reptiles are not two sides of the same coin. Glob Ecol Biogeogr 25:1050-1060. https://doi.org/10.1111/geb.12462

Ulanowicz RE (1995) Trophic flow networks as indicators of ecosystem stress. In: Polis GA, Winemiller KO (eds) Food webs: integration of patterns and dynamics. Chapman and Hall, New York, pp 358-368
Ulanowicz RE (2004) Quantitative methods for ecological network analysis. Comput Biol Chem 28:321-339. https://doi.org/10.1016/j. compbiolchem.2004.09.001

Ulanowicz RE, Kay JJ (1991) A package for the analysis of ecosystem flow networks. Environ Softw 6:131-142. https://doi. org/10.1016/0266-9838(91)90024-K

van der Meer J (2006) An introduction to dynamic energy budget (DEB) models with special emphasis on parameter estimation. J Sea Res 56:85-102. https://doi.org/10.1016/j.seares.2006.03.001

van Kleunen M, Richardson DM (2007) Invasion biology and conservation biology: time to join forces to explore the links between species traits and extinction risk and invasiveness. Prog Phys Geogr 31:447-450. https://doi.org/10.1177/0309133307081295

van Kleunen M, Weber E, Fischer M (2010) A meta-analysis of trait differences between invasive and non-invasive plant species. Ecol Lett 13:235-245. https://doi.org/10.1111/j.1461-0248.2009.01418.x

Vitousek PM, Mooney HA, Lubchenco J et al (1997) Human domination of earth' s ecosystems. Science 277:494-499. https://doi. org/10.1126/science.277.5325.494

Warren PH (1989) Spatial and temporal variation in the structure of a freshwater food web. Oikos 55:299-311. https://doi. org/10.2307/3565588

Woodward G, Ebenman B, Emmerson M et al (2005) Body size in ecological networks. Trends Ecol Evol 20:402-409. https://doi. org/10.1016/j.tree.2005.04.005

Worm B, Barbier EB, Beaumont N et al (2006) Impacts of biodiversity loss on ocean ecosystem services. Science 314:787-790. https://doi. org/10.1126/science.1132294

Yachi S, Loreau M (1999) Biodiversity and ecosystem productivity in a fluctuating environment: the insurance hypothesis. Proc Natl Acad Sci U S A 96:1463-1468. https://doi.org/10.1073/ pnas.96.4.1463
Open Access This chapter is licensed under the terms of the Creative Commons Attribution 4.0 International License (http://creativecommons.org/licenses/by/4.0/), which permits use, sharing, adaptation, distribution and reproduction in any medium or format, as long as you give appropriate credit to the original author(s) and the source, provide a link to the Creative Commons license and indicate if changes were made.
The images or other third party material in this chapter are included in the chapter's Creative Commons license, unless indicated otherwise in a credit line to the material. If material is not included in the chapter's Creative Commons license and your intended use is not permitted by statutory regulation or exceeds the permitted use, you will need to obtain permission directly from the copyright holder. 